\title{
DISTRIBUTION OF GEOLOGISTS AROUND THE WORLD
}

by

Jacques Barroul, Jacques Bodelle and Philippe Rolet

A survey of the worldwide population of geologists was completed for the 26th International Geological Congress this summer. This is the first time that a statistical exercise of this naiure and scale was attempted, and its results shed some light on the profession's disproportionate representation around the world and the varying capacity of its disciplines to cope with and solve regional and global problems.*

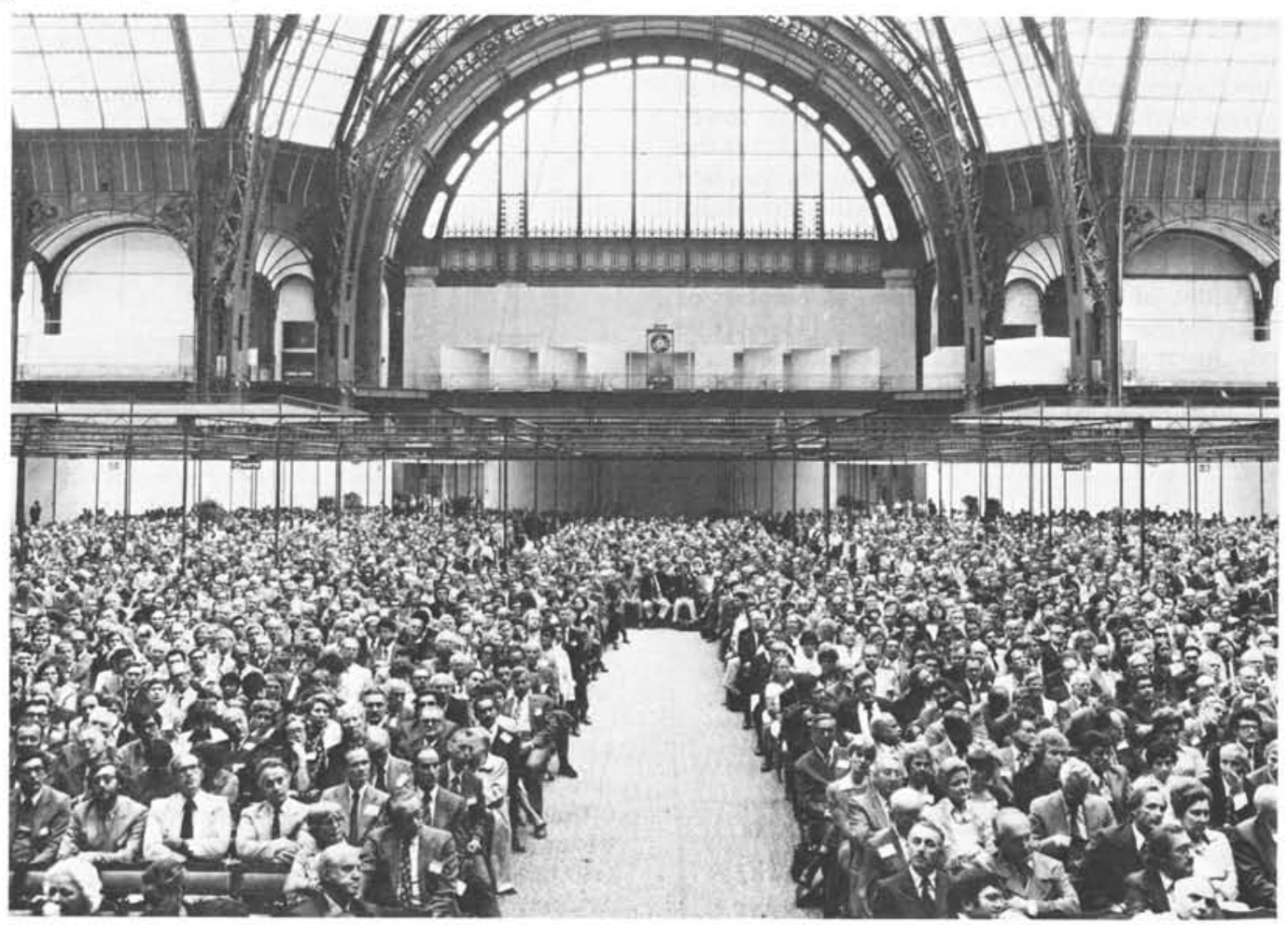

More documentation on geology's worldwide human resources is required; above, one of the largest international geological conclaves assembled in one room - Paris' Grand Palais - hosting 6,000 people at the opening of the 26th IGC.

Data

With the 26th IGC celebrating its centenary in Paris this summer, the Congress Organizing Committee thought it appropriate to review the status of geology - in terms of its manpower - around the world. A questionnaire was sent to the national geological committees (or bodies serving as such) in 141 countries.

This questionnaire was aimed at both technicians and graduate geologists working in the public and private sectors, as well as teachers and researchers in the pure and applied sciences. More specifically, it covered nine areas of specialization: Al: basic - general exploration, geological mapping; A2: related areas - specific types of exploration (geophysical, geochemical, remote sensing...); A3: fringe areas - pedology, geomorphology...; A 4: civil engineering; A5: hydrogeology; A6: energy resources; A7: mining products, mines; A8: quarry products; A9: miscellaneous.

By July 1, 1980, 92 of the 141 questionnaires had been returned and of these 85 were studied in detail, the remainder being incomplete or having arrived after the data had been stored on disc files. In addition, data dealing with technicians could not be incorporated because they were not sufficiently precise and there appeared to be too few technicians to merit detailed examination.

The extent of representation in the responses was fairly high, considering that the 85 countries reviewed make up $63 \%$ of the world's population and $70 \%$ of the continents (excluding Antarctica). A breakdown by continents revealed the following general data:

\begin{tabular}{|c|c|c|c|c|}
\hline Continent & Countries & $\begin{array}{l}\text { \% of } \\
\text { population } \\
\text { represented } \\
\text { in survey }\end{array}$ & $\begin{array}{c}\% \text { of } \\
\text { surface } \\
\text { represented } \\
\text { in survey }\end{array}$ & Geologists \\
\hline $\begin{array}{l}\text { Africa } \\
\text { America } \\
\text { Asia } \\
\text { Europe } \\
\text { Oceania }\end{array}$ & $\begin{array}{r}27 \\
16 \\
14 \\
22 \\
6\end{array}$ & $\begin{array}{l}47 \\
64 \\
56 \\
91 \\
97\end{array}$ & $\begin{array}{l}59 \\
63 \\
54 \\
98 \\
99\end{array}$ & $\begin{array}{r}3623 \\
52518 \\
107255 \\
193225 \\
4196\end{array}$ \\
\hline Total & 85 & 63 & 70 & 360817 \\
\hline
\end{tabular}

These statistics indicate that, on a worldwide basis, there are approximately 140 geologists per million inhabitants.

\footnotetext{
* The complete report, entitled 'Résultats de l'enquête sur la répartition des "géologues" dans le monde' and written by the same authors in collaboration with François Boyer, has been published by the BRGM as report 80 SGN 408 GEO, Orléans, France.
} 
Supplementary data gathered for each country included: (1) the estimated population in 1977 and the surface area; (2) the gross national product (GNP) in dollars for 1977; and (3) the value of mining production in dollars for $1977 \mathrm{ac}-$ cording to estimates published in October 1979, from which the value of energy production has been extracted.

Curiously enough, many large, industrialized countries were able to provide only fragmentary information, to the point where one wondered if the amount of detailed information available concerning geologists in a given country varied inversely with its population size.

\section{Graphs}

Figure 1 relates the number of geologists to the number of inhabitants in the varjous continents; it suggests the following observations: (1) 21 countries in Europe are represented in two separate groups, both of which have positive residuals (that is, a higher number of geologists per number of inhabitants than "average"); (2) 15 countries (out of 27) in Africa are in a group with negative residuals (that is, a lower number of geologists per inhabitants than "average"); (3) the American countries are distributed along the regression line (9 out of 16 having positive residuals); (4) the Asian countries are fairly spread out in two indistinct groups which generally have negative residuals; (5) the countries of Oceania are scattered on both sides of the regression line. A number of countries differ significantly from this line: (1) positive residuals: Iceland, Australia, Canada, U.S.S.R.; (2) negative residuals: Angola, Sri Lanka, Pakistan.

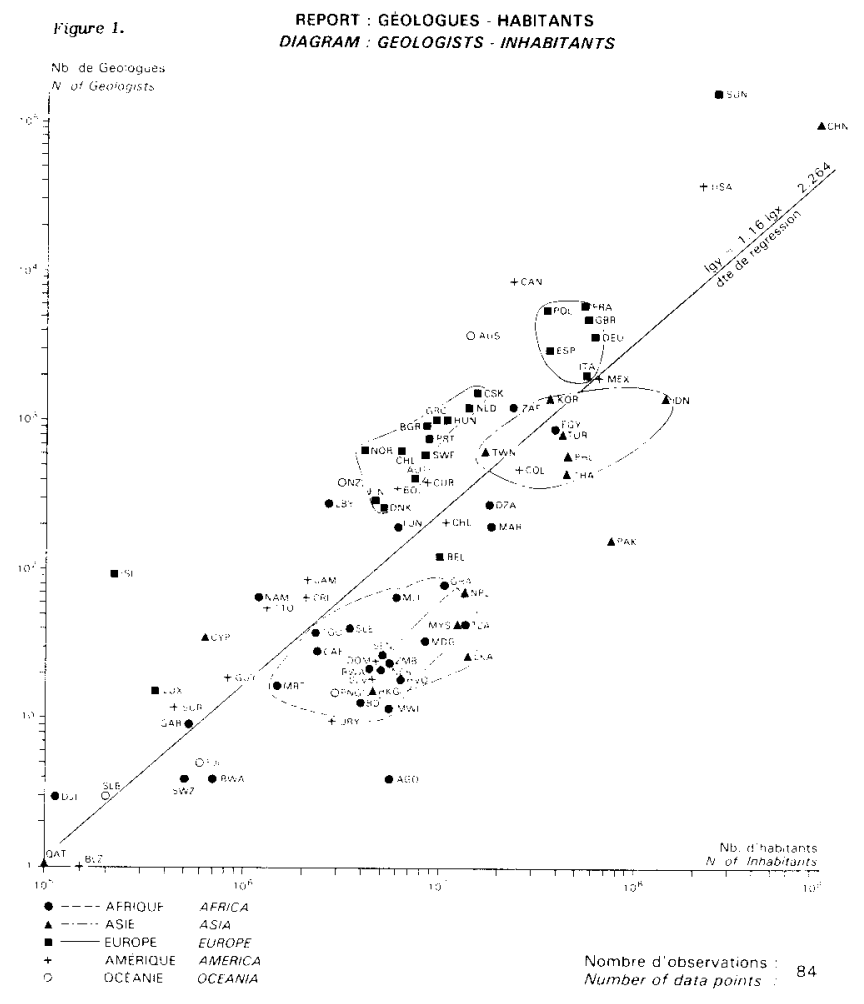

The graph notes the relatively few geologists in African countries as compared to the size of their populations, while conversely, the number of geologists in European and North American countries is significantly higher than the average; in Canada, for example, the ratio is 2.7 times the world average.

Figure 2 relates the number of geologists to the GNP and shows a closer correlation between the two than in Figure 1 (the correlation coefficient being 0.90 as compared to 0.83 ). Countries are generally grouped close to the regression line, forming two continuous elongated zones for Africa and Europe and two distinct groupings for Asia, with China and Qatar as clearly separate entities. With regard to China, it should be pointed out that the response to the questionnaire did not distinguish between geologist and technician, and this may account for the sizeable positive residual. Other large

EPISODES, Vol. 1980, No. 3 residuals worth noting include a positive one for the U.S.S.R., negative ones for Angola, Hong Kong, Qatar and Belgium. The countries of America and Oceania are distributed all along both sides of the regression line. This graph also indicates that the ratio between the number of geologists and the GNP is similar for countries as different as the Republic of Djibouti, Ghana, the U.K. and the U.S.A.

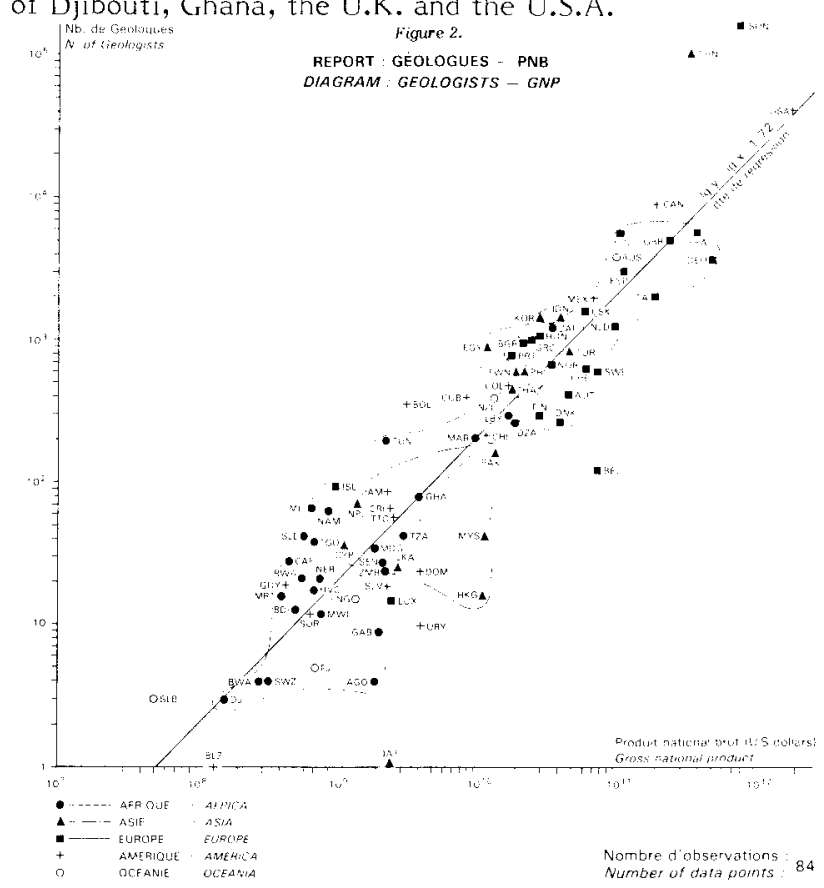

In view of these results, we plotted on a $\log / \log$ scale the number of geologists per capita related to the per capita GNP, but with less success (correlation coefficient: 0.7 ). The graph indicates that the degree of scatter is much greater and the groupings are less distinct. A number of countries differ significantly from the regression line: Angola and Qatar with negative residuals, while China, the U.S.S.R. and Iceland with positive residuals.

The European countries constitute an unusual case among those represented: (a) 10 countries out of 22 have between 83 and 108 geologists per 106 inhabitants, while the per capita GNP ranges from $\$ 2,100.00$ to $\$ 10,000.00$ - a small variation in the number of geologists (25) corresponding to a large variation in per capita GNP $(\$ 7,900.00)$; (b) conversely, 11 countries out of 22 have between 13 and 161 geologists per 106 inhabitants, while the per capita GNP ranges from $\$ 6,000.00$ to $\$ 10,000.00$ - a large variation in the number of geologists (148) corresponding to a relatively small variation in per capita GNP $(\$ 4,000.00)$.

These graphs show that a number of countries (Angola, Qatar, Belgium) have a "deficit" in the number of geologists relative to all the countries represented, although it may be that expatriate geologists were not included in the case of Belgium. To a lesser degree, the same observation may be applied to Sri Lanka, Pakistan, Indonesia and Gabon.

It is of interest that the type of economy (planned or unplanned) appears to have no effect on the number of geologists. Countries of equal "size" (population, GNP) show similar results regardless of the nature of their economy. An attempt to graph the number of geologists in relation to the surface area of the various countries yielded no results of special interest.

\section{Histograms}

In general, the three histograms showing, in per capita terms, the number of geologists, the GNP and the value of mining production, have log normal distributions.

The teaching and research/applied sciences histogram (Fig. 3) has a "J" distribution up to 0.6 , beyond which less precise data give rise to abnormally high ratios and an irregular distribution. Taking these considerations into account and ignoring those countries for which teaching and research are 


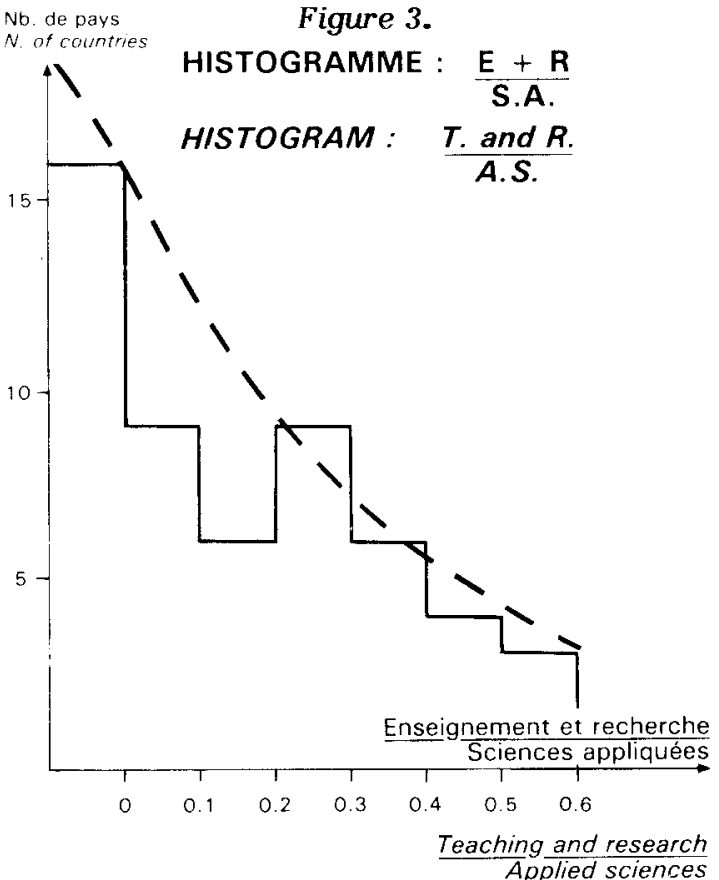

irrelevant, the average value of this ratio can be estimated at $1: 3$, or one researcher/teacher for every three working geologists, representing an effective balance between "theorists" and "practitioners". Many small countries have only working geologists, leaving to the larger countries the tasks of teaching and research. Some industrialized countrics, however, have more theorists than practitioners but at the same time are lacking an established corps of educators.

\section{Factor Analysis}

A factor analysis of the responses covered all the variables (6), each of which was broken down into 5 or 3 categories representing intervals of equal class frequencies. Two factorial axes were defined. The countries were grouped into five zones corresponding roughly to the five regions and arranged in an. ascending order, from left to right, along the first factorial axis: on this plane, all the variables could be replaced by a single one, that of "dimension". Each zone encompasses a certain number of countries, thus defining the "dimension" of each.

The same type of study was conducted on countries which have a planned economy, with all gcologists working in the public sector. On the plane of factorial axes 1 and 2 , there is a contrast between the black African countries on the one hand and the countries of North Africa and eastern Europe on the other. However, the small number of countries studied in this way precludes any generalizations.

\section{Areas of Specialization}

A study correlating the first seven areas of specialization noted above concentrated mainly on energy resources and mining research, as well as the fringe disciplines (pedology, geomorphology), particularly those in the applied sciences.

With regard to the distribution by continent of areas of specialization (Fig. 4-i and Fig. 4-ii), those areas which have the smallest per capita representation of geologists are A.3, $\mathrm{A} 4$ and $\mathrm{A} 5$ (fringe areas, civil engineering and hydrogeology). A4 has been developed to a greater extent than A5 on every continent except for Europe. Note that the horizontal lines (such as MO A2) represent the world averages for a particular specialization.

Hydrogeology and geological engineering seem to have the most even distribution: per million of inhabitants, the number of geologists specializing in these areas does not differ significantly among Africa, Europe and America. Asia alone stands out as an exception and climatic factors may explain this (especially insofar as hydrogeology is concerned).

EPISODES, Vol. 1980, No. 3
Figure 4-i.

DISTRIBUTION DES DISCIPLINES

PAR CONTINENT

DISTRIBUTION OF DISCIPLINES BY CONTINENT

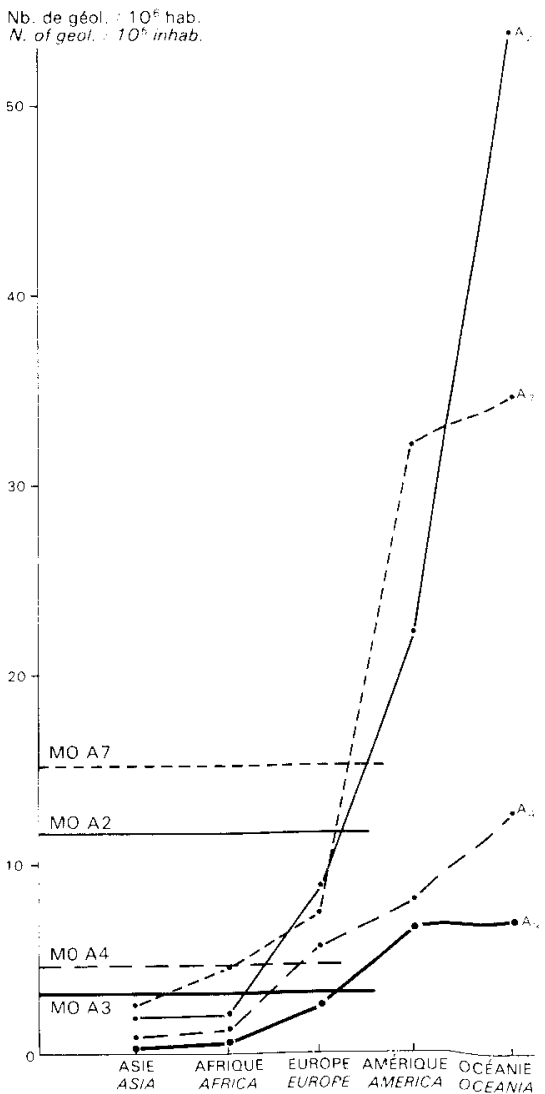

Fiqure 4-ii.

DISTRIBUTION DES DISCIPLINES PAR CONTINENT

DISTRIBUTION OF DISCIPLINES BY CONTINENT

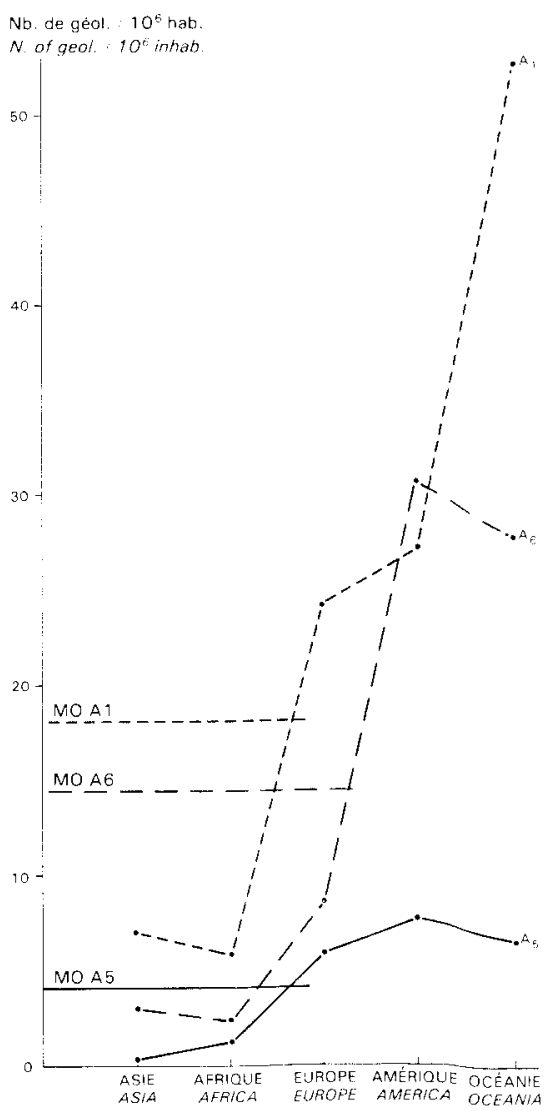




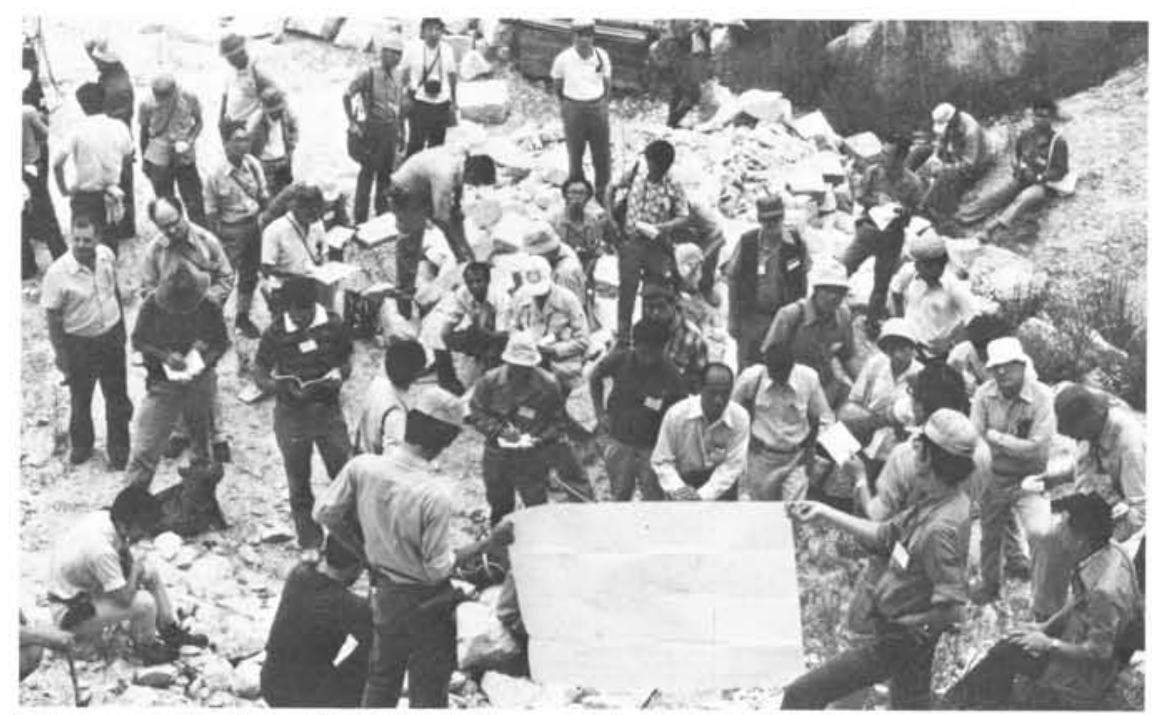

A relatively large percentage (38.5\%) of the world's population of working geologists are in Asia. Here, a group of SE Asian geologists study outcrops in Japan.

Much more pronounced are the differences in terms of the amount of effort expended on general exploration, cartography, and so forth. Europe and America are almost equal, but each has close to three times more geologists per million inhabitants than the rest of the world. These differences are even more pronounced in energy and mining products with America leading by a total of twice as many geologists working on general exploration alone; Europe is in a fairly distant second place.

A study of the relationship between public and private sectors revealed only one grouping: 10 out of 15 African countries have 3 to 11 geologists in the private sector and 4 to 30 in the public sector. With regard to this aspect, replies in general noted the contrasts between the grouping of African countries and that of the highly industralized nations.

\section{ABOUT THE AUTHORS:}

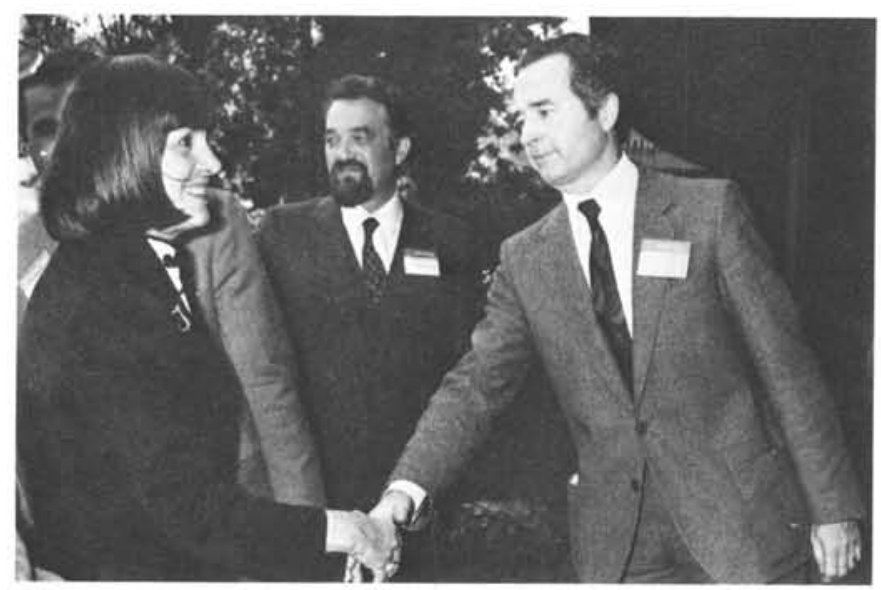

Jacques Bodelle (right) greets Alice Saunié-Seité, Minister of Universities, while Jean Dercourt (centre) another 26 th IGC Vice President and Head of the Congress excursions committee, looks on.

Jacques Bodelle, Vice President of the the 26th IGC and former Director of the Geological Survey at the BRGM in Orléans, is now Scientific Councillor at the French Embassy in Washington, U.S.A. A graduate of the Ecole Polytechnique and the Ecole nationale superieure des Mines, Paris, Dr. Bodelle holds both an engineering degree and a doctorate in natural sciences.

EPISODES, Vol. 1980, No. 3

\section{Total Estimated Number of Geologists}

The survey concluded that in 1977, the world population of working geologists totalled approximately 550000 , distributed as follows: $1.5 \%$ in Africa, $16.5 \%$ in America, $38.5 \%$ in Asia, $42.5 \%$ in Europe, and $1 \%$ in Oceania. A startling observation is that in spite of its enormous size (22\% of the surface area of the continents), Africa has only $1.5 \%$ of the world's geologists. The results of the survey also show that the geological profession is still quite unfamiliar with itself.

In conclusion, we wish to acknowledge that this survey is but a first step toward something that is greatly needed - more detailed, more precise documentation and knowledge of our profession around the world.

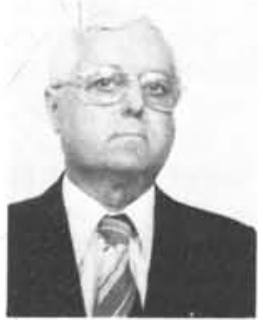

Jacques Barruol is with the Secrétariat de la Carte géologique in the Geological Survey, BRGM in Orléans, France, supervising the production of geological maps and their explanatory notes. A specialist in photogeology, particularly as applied to tropical climates, he worked for several years in French Guyana and in Mali.

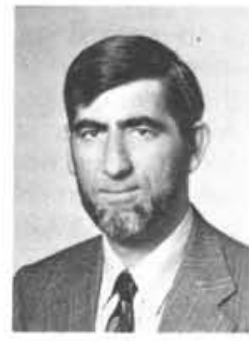

Philippe Rolet has, since 1970, been in charge of statistical enumeration and information services, particularly as applied to geology, at the BRGM in Orléans, France. He is a graduate of the Faculty of Sciences in the Universite Paris VI. 